\title{
EM BUSCA DOS SENTIDOS PRODUZIDOS PELO ATO FOTOGRÁFICO NA VELHICE
}

\author{
Joana Sanches-Justo', Mário Sérgio Vasconcelos ${ }^{2}$ \\ ${ }^{1}$ Docente do curso de Artes Visuais e do curso de Matemática da UNOESTE, doutora em Psicologia. ${ }^{2}$ Docente do curso de Psicologia \\ da UNESP-ASSIS, livre-docente em Psicologia e Educação. Pesquisa financiada pela CAPES. E-mail: joana_sj@yahoo.com.br
}

\section{RESUMO}

Atualmente as pesquisas que envolvem o trabalho com idosos e suas fotografias tendem a valorizar 0 retorno ao passado. Nesta pesquisa pretendemos seguir uma caminho diferente, no sentido de utilizar a fotografia para a valorização do cotidiano e para a prospecção. O objetivo da pesquisa foi investigar os sentidos produzidos pelo ato fotográfico na relação do idoso com o tempo e com a memória, dando maior ênfase às possibilidades da fotografia enquanto prospecção do futuro. Foram realizadas oficinas de fotografia com dois grupos de idosos da cidade de Londrina, uma vez por semana, durante 2 meses. Foi possível verificar que os idosos valorizam mais o cotidiano do que o passado ou o futuro, bem como os amigos, a família e a independência, que também tiveram destaque nas produções fotográficas dos grupos. Palavras-chave: fotografia, idoso,memória, produção de sentidos,psicologia social.

\section{SEARCHING FOR THE MEANINGS PRODUCED BY THE PHOTOGRAPHIC ACT IN OLD AGE}

\begin{abstract}
Currently the researches that involves working with seniors and their photographs tend to value the return to the past. In this research we intend to follow a different path in order to use the picture for the enhancement of daily life and for prospecting. The objective of the research was to investigate the meanings produced by seniors photographic act about time and memory, emphasizing the possibilities of photography while exploring the future. Photography workshops were conducted with two groups of seniors in the city of Londrina, once a week for 2 months. We noticed that the elderly value more the everyday than the past or the future, as well as friends, family and independence, which were also highlighted in the photographic productions of the groups.
\end{abstract}

Keywords: photography, elderly, memory, meaning production, social psychology. 


\section{INTRODUÇÃO E OBJETIVO}

A terceira idade é uma fase da vida que tem sido muito abordada nos tempos atuais. Aos poucos a velhice se torna uma fase repleta de possibilidades, um momento de "recuperar o tempo perdido" e usufruir o tempo ganho com a aposentadoria para investir em si mesmo, viajar, aproveitar a vida. Criou-se todo um mercado para abarcar esta nova fase da vida que toma forma na contemporaneidade: existem lojas de roupas especializadas em vestimentas para a "melhor idade", descontos em agências de turismo, isenção no transporte público, equipes de saúde especializadas em gerontologia e assim por diante.

A lista de serviços e bens de consumo direcionados aos idosos cresce a cada dia,contudo, a velhice é uma fase que provoca desconforto, temos e receio. Algumas pessoas dizem que a velhice é um prêmio, é a mostra de que alguém conseguiu sobreviver até esta altura da vida, superando doenças e outros inúmeros riscos que levaria uma pessoa à morte. Ainda assim, ninguém que ficar velho.

Etimologicamente falando, a palavra idoso diz respeito a uma pessoa que acumulou idade, assim como gostoso é algo cheio de gosto; proveitoso é o que tem muito proveito e assim por diante. No nosso imaginário social, o idoso não significa apenas ter muita idade ou experiência, mas também se refere à uma pessoa que está no fim da vida, que não tem futuro. De acordo com Bosi (1983) é comum associarmos o idoso ao passado, à uma vida sustentada, sobretudo, por recordações de um tempo já vivido.

Por isso, muitas vezes as investigações com esta população envolvem a rememoração. Nas pesquisas qualitativas em ciências humanas, a fotografia é frequentemente usada como ferramenta para a rememoração das estórias da juventude, como se fosse a única possibilidade de trabalho com a terceira idade.
Algumas pesquisas, entretanto, apontam para um caminho diversificado, tomando a velhice como um momento de produções, ressignificações da vida e até mesmo prospecções. Nesse sentido podemos apontar algumas pesquisas, como a de Bruno e Samain (2007) e Bosi (1983).

Bruno e Samain (2007) desenvolveram estudos a respeito da construção da memória na velhice. Realizaram entrevistas e coletaram fotografias dos idosos, que contaram histórias enquanto mostravam seus acervos fotográficos. Posteriormente as fotografias foram organizadas sob a forma de painéis de forma a explicitarem, a partir de diversas configurações espaciais, a vida dos participantes.

Bosi (1983), em seu trabalho "Memória e sociedade: lembranças de velhos", transcreveu os depoimentos de oito pessoas com mais de 70 anos à medida que mostravam algumas fotografias guardadas e a narravam suas lembranças mais antigas.

Apoiando-nos na inovação trazida por estes trabalhos que, cabe aqui ressaltar, acompanham a tendência contemporânea de lançar um novo olhar à terceira idade, realizamos uma pesquisa envolvendo idosos e fotografia. Depois de percorrermos algumas pesquisas que trabalhavam com as memórias dos idosos a partir das fotografias que tinham guardadas, nos perguntamos: "E se o idoso fotografasse as cenas de sua própria vida, o que ele decidiria mostrar?". Nas fotografias guardadas em caixinhas ou álbuns o idoso é sempre o fotografado, mas nunca o fotógrafo. Decidimos, então, dar-lhes voz.

A máquina fotográfica foi 0 instrumento através do qual o idoso pôde se fazer ouvir, contar a sua versão da história e do mundo, através da produção de imagens. Na presente pesquisa a fotografia assumiu um lugar de extrema importância, não apenas como recurso, 
mas como instrumento linguístico e de expressão da subjetividade.

Aqui a fotografia deixou de ser apenas um registro para ser criação ou, como sugere Sontag (2004, p.84), fragmentos que revelam o mundo: "as fotos são, é claro, artefatos. Mas seu apelo reside em também parecerem, num mundo atulhado de relíquias fotográficas, ter o status de objetos encontrados - lascas fortuitas do mundo".

Consideramos, portanto, que as fotografias tornam as experiências da vida mais palpáveis, como por exemplo, quando uma pessoa mostra as fotografias de uma viagem, ela traz aos outros aquela vivência; conta uma versão única dos lugares e pessoas encontradas, das experiências vividas. Outras pessoas viajam com ela através das fotografias, conhecendo lugares sem precisarem ter estado lá.

A fotografia atua na construção da memória, fixando uma imagem como sua extensão e suporte. Organizar e fotografar eventos em nossas vidas são uma maneira de assegurar uma memória coletiva, salvando a experiência do esquecimento. "A memória é vida, sempre carregada por grupos vivos, em permanente evolução, aberta à dialética lembrança/esquecimento" (NORA, 1993, apud LOPES, 2008, p.85).

A fotografia é, portanto, um instrumento interessante a ser utilizado na pesquisa qualitativa, especialmente para dar voz aos sujeitos, já que o ato fotográfico os impele à contemplação e reflexão sobre o sentido do mundo ao nosso redor, possibilitando descrevê-lo através de imagens.

O objetivo da pesquisa foi investigar os sentidos produzidos pelos idosos através do ato de fotografar. A produção de sentidos é um conceito desenvolvido por uma abordagem da Psicologia Social denominado construcionismo social, que vincula a visão de mundo do sujeito ao contexto em que está inserido e ao contato social.
Este posicionamento metodológico considera que a realidade não está dada a priori como objetividade absoluta, mas é construída na interação humana, como processo e se constitui fundamentalmente como produção de sentido. Ao considerar a realidade como uma construção sempre dinâmica, o construcionismo social não se preocupa em alcançar a verdade, pois esta não é nem única, nem neutra, portanto, não é absoluta.

Outro esteio fundamental diz respeito ao papel da linguagem e das relações sociais na produção da "realidade humana", construída a partir dos sentidos que o mundo adquire quando apreendido pela linguagem. No pensamento construcionista, o self, ou seja, a essência do sujeito é constituída na linguagem, mais especificamente na linguagem entre interlocutores.

A ênfase da constituição do sujeito está no contato social, no processo dialógico de conhecer e responder ao outro (RASERA; JAPUR, 2001). Desta forma o sujeito, no contato com o outro, dá sentido ao mundo. A ênfase está no social, como alicerce da produção de sentido, e se contrapõe seja à idéia de que a interpretação do mundo se dá de dentro para fora, seja à idéia contrária. Os sentidos emergem na interação, nas práticas cotidianas, não estando nem no pólo de uma interioridade individual, nem no pólo oposto de determinações objetivas. Emergem, isto sim, na relação do sujeito com outros sujeitos, no entrequeos conecta e os interliga na convivência social. (DUARTE-ALVES; JUSTO, 2007).

A produção de sentidos é uma construção complexa, que acompanha a história de vida dos sujeitos postos na interação e na conversação. Em qualquer momento, interpretamos o mundo ao nosso redor, construímos sentidos e verdades que, posteriormente, podem se transformar ou deixar de existir. Na sua trajetória de vida, o 
sujeito vai tomando suas escolhas, se posicionando, colhendo vivências e criando narrativas que vão formar sua identidade e seu modo de ver o mundo.

\section{METODOLOGIA}

Para alcançar o objetivo da pesquisa, utilizamos, primeiramente, a fotografia como recurso para possibilitar a produção de sentidos e a prospecção. Foram montadas oficinas de fotografia, onde os participantes aprenderam a usar alguns recursos das máquinas fotográficas digitais. Também nas oficinas os idosos tiveram oportunidade de fotografar e de conhecer fotografias de autores renomados, como parte do exercício de construção do olhar e estética fotográficos.

Para as oficinas foram formados dois grupos, o primeiro com aproximadamente com 25 idosos e o segundo, com 5, selecionados no grupo da UNATI (Universidade Aberta à Terceira Idade) da UEL (Universidade Estadual de Londrina).

As oficinas foram divididas em duas partes. A primeira consistiu em oficinas preparatórias com o objetivo específico de exercitar técnicas e o olhar fotográfico. Os participantes foram estimulados a colocar em prática as técnicas discutidas nas oficinas, diversificando temas, situações e recursos da câmera.

A segunda parte consistiu em oficinas temáticas sobre 0 tempo com perguntas disparadoras: "O que você quer, do presente, eternizar para o futuro?" "Que imagem ou cena você registraria agora para representar algo que ainda não aconteceu em sua vida, mas que você pretende que aconteça no futuro?". Nestas oficinas os participantes foram deixados à vontade para fotografarem, exercitando o olhar fotográfico, a autoria e construindo seu próprio estilo, escolhendo imagens, cenas e recursos técnicos.

Cabe ainda ressaltar que o projeto foi aprovado pelo comitê de ética da Universidade Estadual de Londrina (UEL), parecer PF $\mathrm{n}^{\circ}$ 241/09, CAAE nº 0188.0.268.000-09.

\section{RESULTADOS}

Quando pensamos nos velhos e suas fotografias, a imagem que nos vêm à mente é daquele velhinho no asilo, sentado na cama sozinho tendo como único amigo os velhos retratos empoeirados. Agimos dessa mesma forma quando pedimos que nos mostrem suas imagens. É como se lhes fizéssemos um favor, um ato de caridade, ao permitirmos que nos contem suas sagas.

Mas, conforme nossas expectativas, a fotografia foi um instrumento de construção e não de lamentação. O protagonismo do idoso ficou evidente quando, como artistas, produziram obras que contaram as suas versões da história, mostrando-nos seus pontos de vista. Uma participante nos disse, através de suas fotografias, que espera ansiosamente a chegada de seu neto; outra mostrou sua vontade de fazer mais uma viagem, talvez para a Europa ou Japão; outros mostraram fotografias dos amigos, da UNATI, da família ou, ainda, da mão doente que um dia estaria melhor.

De uma forma geral, os grupos produziram imagens relacionadas à atividade, família e à amizade, dentre outras. Um tema que apareceu com frequência foi a viagem, a mobilidade entre tempos e espaços.

Em alguns momentos a fotografia apareceu como um instrumento essencial para o registro de cenas importantes e que, através da fotografia, poderiam ser resgatados e compartilhados. Em outros momentos, o registro não servia apenas para mostrar a vida aos outros mas também ajudava a memória, como um 
suporte: algumas coisas seriam esquecidas caso não fossem fotografadas.

Ficou claro que a fotografia tem um forte vínculo com o sentimento gregário, que confere a grupalidade às pessoas que participam do ato fotográfico, tanto no momento de fazer uma fotografia quanto na hora de revê-la. Na maioria das vezes o ato de olhar fotografias é um momento compartilhado, em grupo, para mostrar ou lembrar algo importante, ou apenas para relembrar momentos prazerosos.

Enquanto mostravam suas fotografias, 0 grupo se identificava com os sentimentos do autor, cada participante comentava suas fotos e também as dos colegas, criando uma dinâmica própria do grupo que instigava a produção de sentidos sobre aqueles momentos e imagens.

A fotografia, que imperativamente resgata um momento do passado, quando é retomada impõe o presente. Podemos então afirmar que a fotografia mostra o passado, mas o ato de olhar fotografias, é realizado no presente. Desta forma, rever fotografias é trazer o passado ao presente, é resgatar experiências e, assim, possibilitar que tais experiências sejam ressignificadas, atualizadas pelo grupo e também por aquele que qs narra.

Nesse sentido, a fotografia permite intervenções no tempo, possibilitando que aqueles que a observam retomem suas histórias e as modifique, atualize, ganhando novos sentidos. Olhar fotografias e comentá-las trouxe muitas vezes 0 resgate da memória, principalmente quando os participantes narraram acontecimentos significativos como casamentos, nascimentos e perdas de entes queridos. Ainda assim, houve a ênfase nas atividades cotidianas, como cuidar da casa, viajar com as amigas, se reunir com a família no final de semana.

\section{DISCUSSÃO}

Tudo o que esteve envolvido no ato fotográfico e na narração das imagens foi produzindo sentidos e memórias. Primeiro, os participantes tiveram que pensar sobre o que iriam fotografar, escolher a cena que melhor representaria seus sonhos, os objetos, o recorte, enquadramento até chegarem ao momento do "apertar o botão". Além dos elementos técnicos envolvidos na produção destas imagens, provavelmente estiveram presentes as lembranças de outros sonhos, alguns realizados outros não.

Quando a fotografia se tornou um instrumento deflagrador de sonhos e da subjetividade do idoso, a narrativa que ela provocou foi pessoal, atada à memória eà histórias de vida que estavam muito além dos objetos fotografados. O ato fotográfico também atuou no espaço pessoal e no tempo da vida dos participantes quando estes se puseram a pensar no futuro e traduzi-lo em imagens.

A memória e a prospecção estiveram lado-a-lado, sendo vivenciadas durante as oficinas, no tempo (presente) da narrativa. Enquanto a narrativa era construída, no aqui e agora do tempo cronológico, os participantes transitavam entre os acontecimentos passados e o que esperavam do futuro, como se não importasse uma delimitação do que é presente, passado ou futuro.

Quando trouxeram imagens relacionadas às prospecções, além de pensarem em sonhos e desejos que se prestariam a realizar num futuro próximo, os participantes também lidaram com os sentidos de esperança, anseio ou medo de fracassar produzidos nesta empreitada.

Podemos fazer uma comparação entre os idosos e os jovens quanto à percepção do futuro: o jovem, quando pensa no futuro, projeta-se para um tempo vindouro, para o momento em que, 
finalmente, poderá alcançar aquilo que almejou há tempos.

Para os idosos que narraram suas imagens a ênfase foi dada a acontecimentos que já haviam se iniciado e que perdurariam ou teriam certo efeito em algum tempo adiante, como no caso da senhora que mostrou as fotos da filha grávida. Ela apresentou tais imagens para mostrar a família, a filha e seu neto vindouro. Não selecionou as imagens pensando no que era importante para o futuro, mas quando questionada sobre suas prospecções, disse que 0 que espera do futuro é seu neto.

Ficou evidente que os idosos esperam do futuro algo mais concreto do que os anseios juvenis, que delimitam uma forma particular (e já muito mercantilizada ou estigmatizada) de pensar o futuro, um tempo tão distante e promissor. Nas oficinas, o futuro apareceu logo ali, ao alcance dos olhos, e dos sonhos.

Assim, percebemos que o presente é mais significativo que o passado, e o futuro é um momento de continuidade dos sonhos e anseios já iniciados no presente.

\section{CONCLUSÃO}

A velhice muitas vezes está associada à doença, mobilizando um amplo espectro de especialistas na busca da juventude eterna e, portanto, no combate ao envelhecimento. Hoje almejamos a vida eterna desprovida de morte e não mais a vida eterna após a morte. Não basta viver para sempre, há que ser eternamente jovem.

Na sociedade contemporânea não existe lugar para uma fase da vida próxima da doença, do fim, da morte. Talvez por isso existe a insistência em afastar a todo custo o idoso da proximidade com a finitude, criando grupos de terceira idade, grupos de excursões, academias para idosos etc. Claro que isso traz uma visão mais positiva da velhice e do envelhecer, mas também exclui o que à vida é mais intrínseco: a morte. Lidar com a morte não é deixar-se consumir pelo desamparo ou luto, mas, ao contrário, é justamente a morte que nos impulsiona à vida. Sem pensar no curto tempo que nos resta, não haveria motivo para implicarse no ato de viver.

Talvez soe paradoxo, mas podemos pensar que aquele que está mais próximo da morte é também o maior agente (ou protagonista) da vida. Produzindo leituras do mundo através da fotografia, os idosos participantes da nossa pesquisa assumira um lugar privilegiado de agentes potencializadores da vida, mesmo no contato com a morte. A morte, como havia de ser, esteve presente em vários momentos. Ficou claro que a fotografia não pode escapar à morte assim como dela não escapam os idosos ou qualquer outro vivente.

No contato com os idosos, dentro das oficinas, pudemos testemunhar que eles podem ocupar um lugar privilegiado de agentes potencializadores da vida; que podem criar novas formas de pensar o mundo e de viver. Tótora (2011) acentua o quanto o idoso pode se tornar um artista que faz releituras da própria vida e do mundo, com seu olhar diferenciado que atravessa a memória e se lança prospectivamente para o futuro. Através da criatividade artística é possível reescrever narrativas, criar novas versões dos acontecimentos, manipular o encadeamento do tempo.

Os participantes, em posse da máquina fotográfica, produziram imagens sobre a vida. A eternização e o congelamento inerentes à imagem fotográfica, paradoxalmente, possibilitaram produções de sentidos sobre a vida. Estas produções estiveram intimamente relacionadas não ao idoso como um ser estagnado, perdido em meio à aceleração da vida contemporânea, mas, muito pelo contrário 
completamente adaptado à velocidade com que as coisas acontecem atualmente.

Assim como Tótora (2011), podemos pensar o idoso como um artista capaz de olhar a vida com outros olhos, mais criativos e livres dos estereótipos sociais que ditam como um velho deve se portar. A fotografia pode ser justamente um dispositivo facilitador para este propósito. A máquina fotográfica hoje está tão popularizada que perdeu seu status de ferramenta, equipamento ou instrumento artístico, utilizado exclusivamente por profissionais.

Sendo um objeto do cotidiano, talvez familiar para a maioria dos idosos que participaram da pesquisa, a máquina fotográfica pode se prestar a despertar novos olhares, incentivando o idoso a experimentar-se como artista da própria vida. O que pretendíamos com as oficinas realizadas com idosos não era revelar novos fotógrafos, mas explorar olhares mais criativos sobre o mundo. Pensamos que olhar atentamente 0 mundo permite ressignificar os acontecimentos da vida, produzir novas narrativas e situá-los transgressivamente no tempo, tal como fazem os artistas.

Colocar a máquina fotográfica nas mãos dos idosos é provocar novas intervenções e transgressões. Transgredir ideias fixas a respeito da decrepitude da velhice e também a respeito da estática da fotografia.

\section{REFERÊNCIAS}

BOSI, E. Memória e sociedade: lembranças de velhos. São Paulo: T. A. Queiroz, 1983.

BRUNO, F.; SAMAIN, E. G. Una cartografía Verbo-Visual de la Vejez. Fotobiografias y montajes de memorias. Revista Chilena de Antropología Visual, v. 10, p. 1-15, 2007.

DUARTE-ALVES, A.; JUSTO, J. S. Saberes no cotidiano: práticas discursivas e transdisciplinaridade. In: CONSTANTINO, E. P. (Org.). Percursos da pesquisa qualitativa em psicologia. São Paulo: UNESP/Arte \& Ciência, 2007. p. 61-78.
LOPES, S. C. Imagens de um lugar de memória da educação nova: Instituto de Educação do Rio de Janeiro nos anos de 1930. Revista Brasileira de Educação, v.13, n.37, p. 84-97, 2008.

RASERA, E.; JAPUR, M. Contribuições do Pensamento Construcionista para o Estudo da Prática Grupal. Psicologia: Reflexão e Crítica, Ribeirão Preto, v.14, n.1, p. 201-209, 2001.

SONTAG, S. Sobre fotografia. São Paulo: Companhia das Letras, 2004.

TÓTORA, S. M. C. Invenções da velhice. Revista Portal de Divulgação, v. 15, p. 11-17, 2011. 